\title{
Pediatric Scaphoid Nonunions: A Case Series, Review of the Literature, and Evidence-Based Guidelines
}

\author{
Kerstin Oestreich, MD, MSc ${ }^{1}$ Tatiana Umata Yoko Jacomel, MD ${ }^{1}$ Sami Hassan, FRCS ${ }^{2,3}$ \\ Maxim David Horwitz, FRCS ${ }^{2}$ Tommy Roger Lindau, MD, PhD ${ }^{3}$ \\ ${ }^{1}$ Hand and Upper Limb Service, Department of Plastic Surgery, \\ Birmingham Women's and Children's Hospital, Birmingham, \\ United Kingdom \\ ${ }^{2}$ Hand Unit, Chelsea and Westminster Hospital, London, United Kingdom \\ 3 Pulvertaft Hand Centre, Kings Treatment Centre, Royal Derby \\ Address for correspondence Kerstin Oestreich, MD, MSc, Hand and \\ Upper Limb Service, Department of Plastic Surgery, Birmingham \\ Women's and Children's Hospital, Steelhouse Lane, Birmingham, \\ B4 6NH, United Kingdom \\ (e-mail: kerstin.oestreich@nhs.net; kerstin.oestreich@live.co.uk).
}

Hospital, Derby, United Kingdom

J Wrist Surg 2020;9:2-12.

\begin{abstract}
Keywords

- pediatric

- scaphoid

- nonunion

- pseudarthrosis

- outcome

Background Scaphoid fractures represent less than 3\% of hand and wrist fractures in the pediatric population. Nonunions are very rare. We present a case series $(n=18)$ of nonunions in skeletally immature children and adolescents. We further present a review of the literature on pediatric scaphoid nonunions.

Materials and Methods We reviewed the literature by searching the main databases on pediatric scaphoid nonunions, but to identify factors that lead to nonunion, we also searched for databases on scaphoid fractures. Seventy articles were found for the period between 1961 and 2019, all with level 4/5 evidence.

Results The nonunion rate of pediatric scaphoid fractures in the literature is on average $1.5 \%$, occurring mostly as a result of missed or underdiagnosed injuries, similar to our presented case series. Half $(n=9)$ of the injuries in our case series were missed initial injuries, leading to scaphoid nonunions and half developed nonunions after initial treatment. We found excellent outcomes and with surgical and nonoperative management, with few complications. Not surprisingly, the duration of immobilization is longer with nonoperative management.

Conclusions Based on the literature, we recommend a period of nonoperative management before surgery in undisplaced nonunions. In displaced nonunions, open reduction and internal fixation \pm bone grafting is necessary. In pediatric scaphoid fractures, similar to adult cases, we identified that suspicious scaphoid fractures should be considered for initial immobilization, and repeat X-rays and early magnetic resonance imaging (MRI) or computed tomography (CT) scans should be considered at follow-up. Immobilization time and type of plaster should be appropriate in relation to the fracture site, similar to the adult scaphoid fracture.

Level of Evidence This is a Level IV study.
\end{abstract}

Fractures of the scaphoid are rare events representing between 0.3 and $0.4 \%$ of all pediatric fractures. ${ }^{1-9}$ The scaphoid is affected in 2 to $3 \%$ of pediatric hand and wrist fractures, ${ }^{4-7,10,11}$ albeit it is the most often affected carpal bone in the pediatric population (87\%). ${ }^{7}$ It most commonly affects adolescents between 11 and 17 years of age $\mathrm{e}^{2,4,7,10,12-14}$ and very rarely children younger than 8 years. ${ }^{2,4,7}$ These injuries may become more common as children take part in more sporting activities, ${ }^{7,15-17}$ and possibly also with an increase in body mass index (BMI). ${ }^{7}$ received

August 9, 2019

accepted after revision

November 1, 2019

published online

December 24, 2019
Copyright $\odot 2020$ by Thieme Medical

Publishers, Inc., 333 Seventh Avenue, New York, NY 10001, USA. Tel: +1(212) 760-0888.
DOI https://doi.org/ 10.1055/s-0039-3401035. ISSN 2163-3916. 
Pediatric scaphoid fractures have an excellent prognosis once and if acutely diagnosed. Nonunions are exceedingly rare, and management of such cases varies widely throughout the literature, ranging from plaster immobilization to osteosynthesis, with or without bone graft.

The aim of this study was to present a case series with various treatments, all leading to a successful outcome, review the literature on both pediatric scaphoid fractures and nonunions, and, based on these two, present both experience- and evidence-based guidelines for the management of pediatric nonunions of the scaphoid.

\section{Materials and Methods}

\section{Case Series}

We included 18 pediatric patients ( 15 boys and 3 girls) from three units (-Table 1) who presented with delayed or nonunion of the scaphoid with a mean age of 13 years (range: 9-15 years). The trauma mechanism was falling onto an outstretched hand (FOOSH) in six patients, hyperextension or hyperflexion trauma while playing football/rugby in six patients, crush injury in two patients, falling off a horse in one patient, and unclear in three patients. Of the 18 patients, there was an initial diagnosis of a scaphoid fracture in 9 and of "sprain" in 4; 10 of these 13 patients had some form of initial immobilization due to the initial presentation. Five patients did not have any initial review and subsequently no initial treatment (-Fig. 1).

Diagnosis and start of treatment of the nonunions was 8 months (range: 2-28 months) after initial trauma. The nonunions were undisplaced waist in 11 children; six were in the proximal pole and one in the distal pole. All children underwent plain X-rays for diagnosis, as well as additional imaging (magnetic resonance imaging [MRI] $=13$ and/or computed tomography $[\mathrm{CT}]=14)$. Patients were treated nonoperatively with immobilization alone $(n=6)$, screw fixation and bone graft $(n=6)$, screw fixation without bone graft $(n=2)$ (-Fig. 1), and K-wires and bone graft $(n=2)$ ( graft, if used, was taken either from the iliac crest or the distal radius. One patient was immobilized for 6 weeks after initial trauma and remained asymptomatic in spite of partial union/nonunion on X-ray (-Fig. 2). One patient was initially diagnosed as a child (below the age of 16 years) but was further followed-up within the adults department.

All patients were asymptomatic after treatment, and healing was achieved in 16 cases, as confirmed with CT in $13 / 16$ cases.

\section{Material and Methods}

\section{Review of the Literature: Pediatric Scaphoid Nonunions}

We reviewed the literature on pediatric scaphoid nonunion and their management. We further added management of pediatric scaphoid fractures for completion and identifiable factors to avoid nonunions (-Table 2 ).

Seventy articles were found for the period between 1961 and 2019. None of them was level 1 to 3 evidence, that is, prospective randomized studies, prospective series, or comparison studies. All articles found were either case series (level 4) or cases with reviews (level 5).

\section{Results and Integrated Discussion}

\section{Pediatric Scaphoid Nonunions}

The nonunion rate of pediatric scaphoid fractures in the literature is on average 1.5\% (range: $0-4.3 \%$ ) (-Table 3 ). Scaphoid nonunion is usually a result of a missed or neglected injury or an underdiagnosed fracture, ${ }^{24}$ similar to our presented case series. The mean age of children reported with scaphoid nonunions is 13 years following a systematic review of 176 pediatric scaphoid nonunions in the literature ( - Table 4), also similar to that in our case series.

There is no standard duration of time that it takes for a pediatric or adolescent scaphoid fracture to be classified as delayed union or nonunion. ${ }^{17}$ Most commonly, nonunion is defined as the absence of bony union at least 3 months after injury. ${ }^{5,17-19}$ However, others take a more adult view and define it as 6 months after the injury. 1,6,18 Furthermore, others believe that the definition of scaphoid nonunion is the presence of cystic changes of the scaphoid or sclerosis of the bone ends around the radiolucent line at the fracture site seen on standard radiographs at least 3 months after injury. $^{5,18,20}$ In a recent paper, ${ }^{21}$ it has been implied that nonunion is a displacement of scaphoid fracture fragments more than $1 \mathrm{~mm}$ on CT scans, with signs of cystic resorption and sclerosis on radiographs and CT scans occurring later than 6 weeks after scaphoid fractures. ${ }^{21}$

In regard to this controversy, we have defined delayed healing in our case series as 6 weeks after injury in the skeletally immature patients in whom healing potential is better than that in adults, suggesting that a nonunion type of management should be considered at 6 weeks after injury in the pediatric population.

Two types of pediatric scaphoid nonunions have been suggested. ${ }^{4,14,22}$ The first group (42\%) includes those correctly diagnosed at the time of injury and treated, but where failure of union occurs despite adequate treatment. The second group (58\%) involves completely missed injuries, inadequately investigated injuries with a combination of lack of awareness about the possibility of pediatric scaphoid fractures and the difficulty in examining young patients. Some nonunions are simply incidental findings on radiographs for other pathology. ${ }^{23,24}$

\section{Management of Pediatric Scaphoid Nonunions}

\section{Nonoperative Treatment of Pediatric Scaphoid Nonunions}

In adults, the preferred management for a scaphoid nonunion is open reduction internal fixation (ORIF). ${ }^{25}$ In children, it has been suggested that a trial of cast immobilization be attempted first ${ }^{1,7,26}$ due to the fact that the pediatric scaphoid fractures have a more favorable healing capacity than adult fractures. The average time for immobilization is 15 weeks (-Table 5). Almost all nonunions involved the scaphoid waist. ${ }^{23}$ Most of the fractures had been neglected 


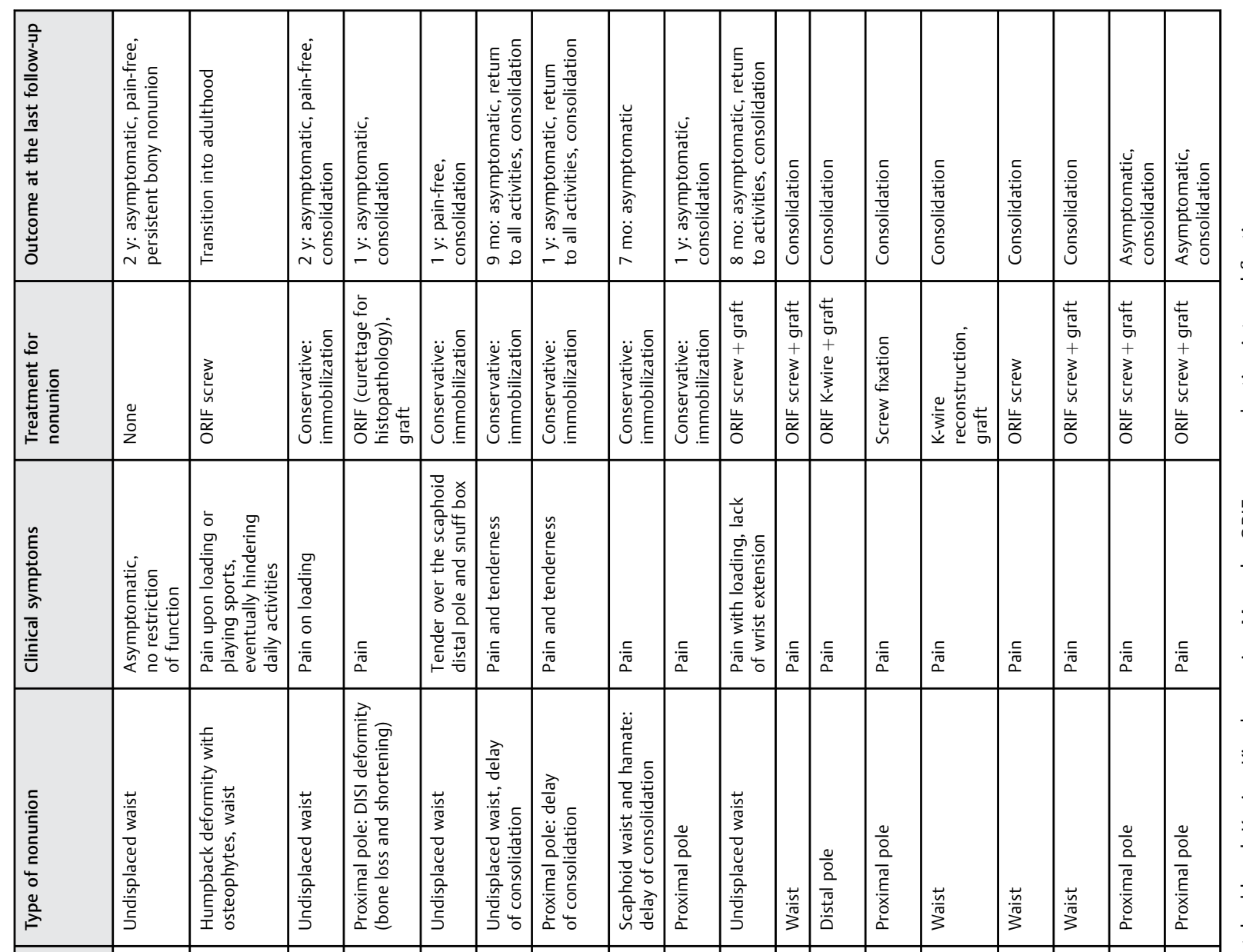

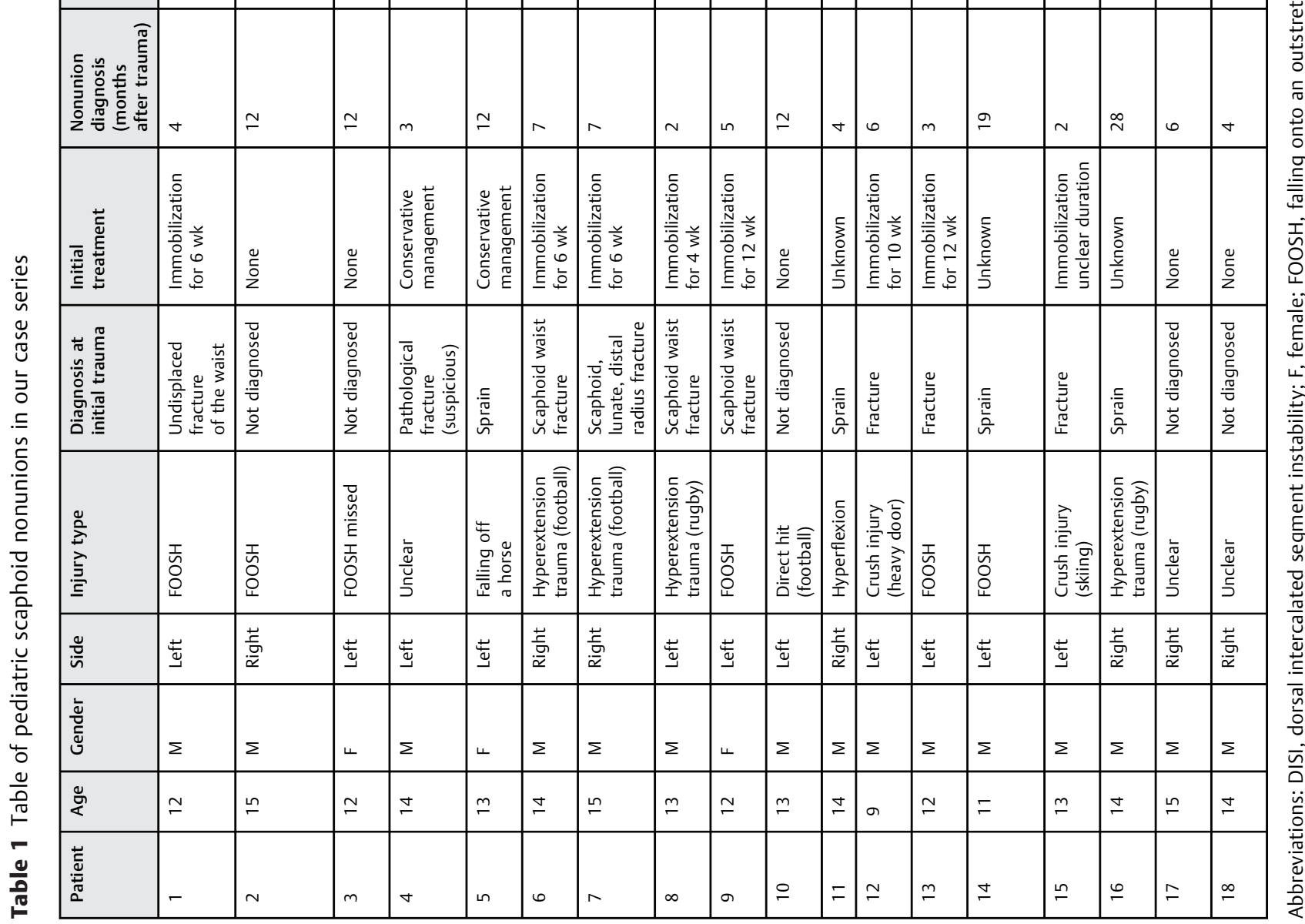

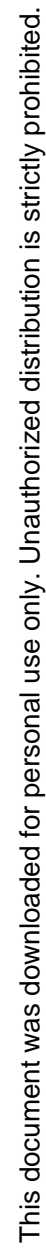



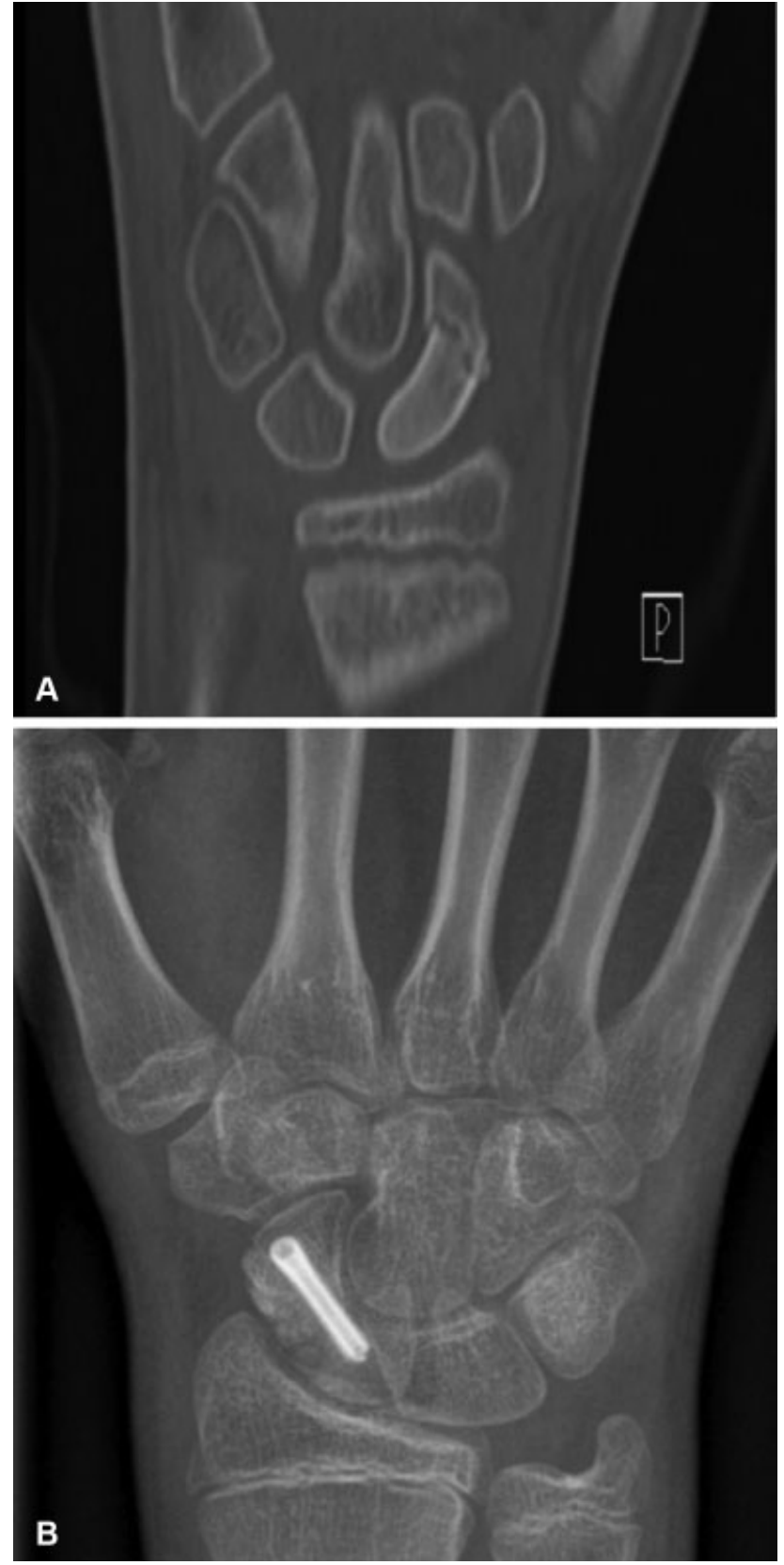

Fig. 1 (A) A 14-year-old boy had a hyperextension injury treated as a sprain. Four months later, he presented with a painful wrist and a scaphoid nonunion of the waist that was diagnosed with computed tomography (CT). (B) He was treated with open reduction internal fixation with screw fixation, which led to consolidation.

without initial immobilization at the time of injury. Further causes of failure to achieve bony union may be noncompliance (with immobilization, no loading instructions, etc.) and inadequate length of immobilization. ${ }^{17,27,28}$

Immediate treatment of an early diagnosed pediatric scaphoid fracture using cast results in radiographic healing in more than $90 \%$ of cases. ${ }^{17}$ In patients with a delay in diagnosis and thereby in treatment (more than 6 weeks), chances of healing are reduced to $23 \%$ with nonoperative management. ${ }^{17}$

Complications after plaster treatment in children are infrequent, with rare examples of malunion, "deformity,"
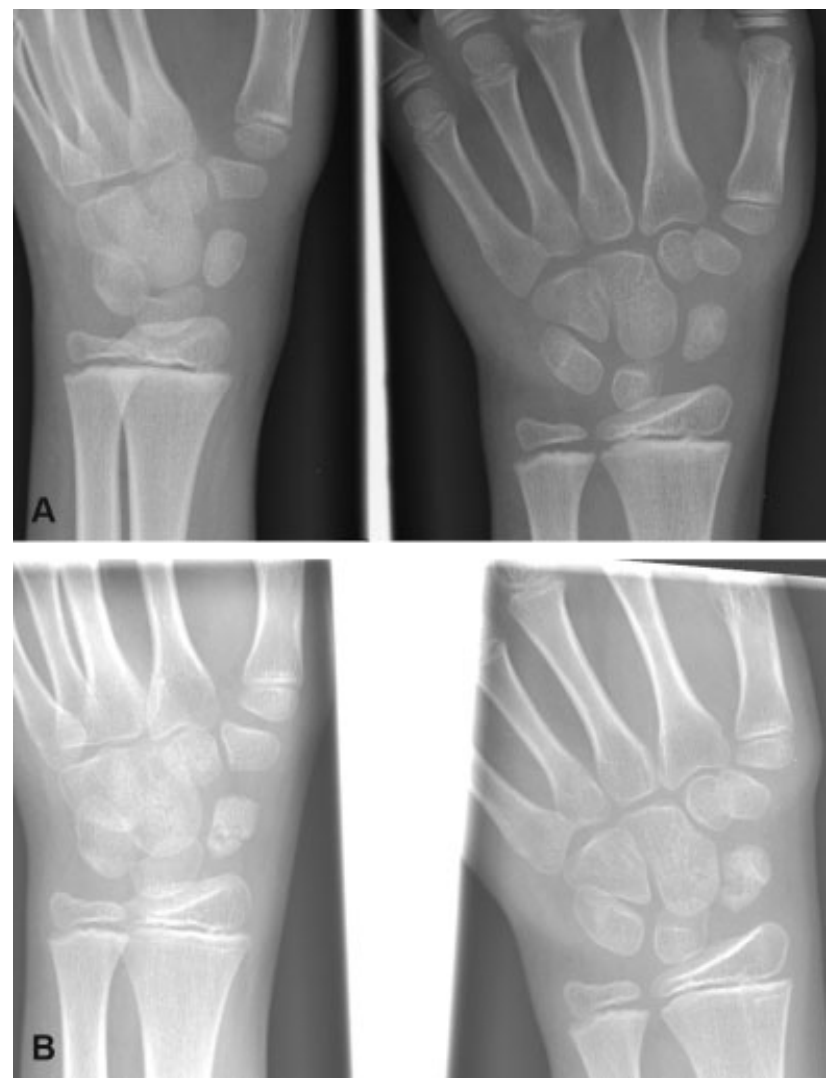

Fig. 2 (A) A 12-year-old boy presented after falling from a standing height onto his wrist, sustaining an undisplaced fracture of the waist of the scaphoid. (B) After 6 weeks of immobilization in a below-elbow scaphoid cast, the patient was mobilized, yet after 16 weeks (as shown here), there was still an undisplaced partial union/nonunion of the waist of the scaphoid, however, without any clinical symptoms or restriction of function compared with the other wrist.

Table 2 Our literature search with further cross-searches with check words based on findings

\begin{tabular}{|l|l|}
\hline Search engines & $\begin{array}{l}\text { MEDLINE, EMBASE, CINAHL, } \\
\text { PubMed, Cochrane }\end{array}$ \\
\hline $\begin{array}{l}\text { Age-related } \\
\text { search words }\end{array}$ & $\begin{array}{l}\text { Pediatric, pediatric, skeletally } \\
\text { immature, growing skeleton, } \\
\text { immature skeleton, child, children, } \\
\text { infant, adolescent, youth, } \\
\text { young adult, infant }\end{array}$ \\
\hline $\begin{array}{l}\text { Diagnosis-related } \\
\text { search words }\end{array}$ & $\begin{array}{l}\text { Scaphoid, scaphoid bone, } \\
\text { carpal bones, fracture, nonunion, } \\
\text { malunion, nonunited, malunited, } \\
\text { delayed healing, pseudarthrosis }\end{array}$ \\
\hline $\begin{array}{l}\text { Outcome-related } \\
\text { search words }\end{array}$ & Treatment, outcome \\
\hline
\end{tabular}

Abbreviations: CINAHL, Cumulative Index to Nursing and Allied Health Literature; EMBASE, Excerpta Medica Database.

and decrease in wrist extension noted clinically. ${ }^{27,29}$ Stiffness is rarely an issue in the pediatric population. ${ }^{4,16}$ There are no reports of failure with nonoperative treatment of pediatric scaphoid nonunions. In children, a trial of immobilization can be recommended, although a long period of time to union should be expected ( - Table 5 ). Our case series 
Table 3 Nonunion rate from the largest published series in children and adolescents (\%)

\begin{tabular}{|c|c|c|}
\hline Authors & $\begin{array}{l}\text { Number } \\
\text { of cases }\end{array}$ & Nonunions \\
\hline Vahvanen and Westerlund ${ }^{54}$ & 108 & 0 \\
\hline Mussbichler $^{8}$ & 100 & 2 \\
\hline Nafie $^{36}$ & 72 & 1 \\
\hline Christodoulou and Colton $^{9}$ & 64 & 1 \\
\hline D'Arienzo $^{47}$ & 39 & 0 \\
\hline Wulff and Schmidt ${ }^{50}$ & 34 & 1 \\
\hline Fabre et al ${ }^{22}$ & 23 & 2 \\
\hline Stanciu and Dumont ${ }^{45}$ & 21 & 0 \\
\hline Total & 461 & 7 \\
\hline Percentage & $100 \%$ & $1.5 \%$ \\
\hline
\end{tabular}

included six children, all of whom healed after immobilization alone without complications.

\section{Surgical Treatment of Pediatric Scaphoid Nonunions}

Surgical management of pediatric scaphoid nonunions has been found to be successful for over 40 years ${ }^{29,30}$; hence, surgical management has become more widely accepted in the pediatric population.

Surgical management of pediatric scaphoid nonunions was found in 153 children in our literature search, with ORIF, autogenous bone graft, and screw fixation being the most common methods (-Table 6 ) similar to adults. Other techniques included various combinations such as autogenous bone graft without fixation, ${ }^{30-33}$ bone graft with K-wire fixation, ${ }^{24,31,33-37}$ ORIF and lag screw fixation, ${ }^{29,31}$ and closed reduction and percutaneous screw fixation (-Table 6). ${ }^{17,31,38,39}$

All surgical techniques have proven to be successful (-Table 6). The principal difference has been the length of postoperative immobilization (-Table 6 ). The shortest immobilization periods required for union have been associated with ORIF. ${ }^{31}$ In select series of fibrous nonunion, union was seen within only 3 weeks using percutaneous screws without graft $^{29}$ (- Table 6). It has been shown that ORIF halved the postoperative immobilization period when bone graft was used. ${ }^{31,33}$ However, the length of postoperative immobilization with osteosynthesis is comparable to all other operative series. There is a revision rate of approximately 3\% in all surgical techniques. ${ }^{17}$ Other complications reported include proximal migration of screws, malunion, pin-site infection, and restriction of wrist movements compared with the contralateral wrist ( - Table 6). ${ }^{\text {17,29,31-33,37 }}$

An important technical aspect is that there has been some concern about the use of compression screws in children because of the ossification pattern with the cartilage cap of the scaphoid (-Fig. 3). ${ }^{23,32,39}$ However, ORIF with screw fixation has the advantages of strong internal fixation with compression, prevention of scaphoid collapse, and reduction of the time of postoperative immobilization. ${ }^{23}$ However,
Table 4 Summary of reported pediatric scaphoid nonunion cases with the mean age

\begin{tabular}{|c|c|c|c|}
\hline \multirow[t]{2}{*}{ Authors } & \multirow{2}{*}{$\begin{array}{l}\text { Number } \\
\text { of Nonunions }\end{array}$} & \multicolumn{2}{|c|}{ Age (years) } \\
\hline & & Mean & Range \\
\hline Jernigan et al ${ }^{46}$ & 1 & 13 & \\
\hline Bae et $\mathrm{al}^{15}$ & 24 & & $8-18$ \\
\hline Carlson et $\mathrm{al}^{55}$ & 14 & & $12-17$ \\
\hline Behr et $\mathrm{al}^{21}$ & 7 & 12.8 & $10.8-13.4^{56}$ \\
\hline Gajdobranski et al ${ }^{14}$ & 3 & & \\
\hline $\begin{array}{l}\text { Southcott } \\
\text { and Rosman }\end{array}$ & 2 & & $14-15$ \\
\hline Gomes et al $1^{12}$ & 1 & 15 & \\
\hline Masquijo and Willis ${ }^{20}$ & 23 & 15.1 & \\
\hline Weber et $\mathrm{al}^{27}$ & 6 & 12.8 & $9.7-16.3$ \\
\hline Jeon et $\mathrm{al}^{38}$ & 2 & 13.15 & \\
\hline lqbal et al ${ }^{57}$ & 1 & 11 & \\
\hline Chloros et $\mathrm{al}^{23}$ & 12 & 13 & $9-15$ \\
\hline Clarke et $\mathrm{al}^{10}$ & 1 & 11 & \\
\hline Duteille and Dautel ${ }^{24}$ & 11 & 12.2 & $9-15$ \\
\hline Toh et $\mathrm{al}^{29}$ & 46 & 13.9 & $11-15$ \\
\hline $\begin{array}{l}\text { Henderson } \\
\text { and Letts }\end{array}$ & 20 & 15.2 & $14-18$ \\
\hline García-Mata $^{32}$ & 4 & 12.6 & $10-15.5$ \\
\hline Waters and Stewart ${ }^{34}$ & 3 & 14.8 & $14-15$ \\
\hline Fabre et $\mathrm{al}^{22}$ & 2 & 9.25 & $8.5-10$ \\
\hline Mintzer and Waters ${ }^{33}$ & 13 & 13.1 & $9-15$ \\
\hline Wulff and Schmidt ${ }^{50}$ & 1 & 14.5 & \\
\hline Godley $^{60}$ & 1 & 12 & \\
\hline Barton $^{40}$ & 1 & 9 & \\
\hline Littlefield et al $^{61}$ & 2 & 10 & \\
\hline Mintzer et $\mathrm{al}^{39}$ & 5 & 12.7 & $10-14$ \\
\hline Caputo et $\mathrm{al}^{35}$ & 1 & 9 & \\
\hline De Boeck et al ${ }^{53}$ & 1 & 8.5 & \\
\hline Larson et al ${ }^{58}$ & 1 & 5.9 & \\
\hline Nafie $^{36}$ & 1 & 14 & \\
\hline Wilson-MacDonald ${ }^{28}$ & 1 & 11 & \\
\hline $\begin{array}{l}\text { Christodoulou } \\
\text { and Coulton }\end{array}$ & 1 & 11 & \\
\hline Greene et $\mathrm{al}^{26}$ & 4 & 10.75 & $6-14$ \\
\hline Pick and Segal ${ }^{59}$ & 1 & 8 & \\
\hline Maxted and Owen ${ }^{37}$ & 2 & 12.75 & $12.5-13$ \\
\hline Onuba and Ireland ${ }^{42}$ & 2 & 14 & $13-15$ \\
\hline $\begin{array}{l}\text { Southcott } \\
\text { and Rosman }\end{array}$ & 8 & 12 & $9-14$ \\
\hline Mussbichler $^{8}$ & 2 & Unknown & \\
\hline Total & 242 & 11 & \\
\hline
\end{tabular}

these screws have been used successfully in children as young as 9 years, ${ }^{23,33}$ and only one proximal migration has been reported ${ }^{31}$; yet the choice of inserting a screw is a very important part of the preoperative planning in particular 
Table 5 Nonoperative management of pediatric scaphoid nonunions found in our search

\begin{tabular}{|c|c|c|c|c|}
\hline Authors & Number of cases & Age (years) & Length of immobilization (weeks) & Complications \\
\hline Jernigan et al $^{46}$ & 1 & 13 & $\begin{array}{l}14+\text { low-intensity } \\
\text { pulsed ultrasound }^{55}\end{array}$ & Nil \\
\hline Weber et $\mathrm{al}^{27}$ & 6 & $\begin{array}{l}9.7-16.3 \\
\text { (Mean: 12.8) }\end{array}$ & $12-28$ & $\mathrm{Nil}$ \\
\hline Greene et $\mathrm{al}^{26}$ & 2 & $6.5-14$ & $10-20$ & Nil \\
\hline Fabre et $\mathrm{al}^{22}$ & 2 & $8.5-10$ & $6-14$ & Nil \\
\hline Toh et $\mathrm{al}^{29}$ & 2 & $11-15$ & $5-6$ & $\begin{array}{l}\text { Deformity with } \\
\text { distal pole nonunion }\end{array}$ \\
\hline De Boeck et $\mathrm{al}^{53}$ & 1 & 8.5 & 14 & $\mathrm{Nil}$ \\
\hline Godley $^{60}$ & 1 & 12 & $\begin{array}{l}24+\text { PEMF stimulation } \\
\text { for } 12 \mathrm{wk}\end{array}$ & $\mathrm{Nil}$ \\
\hline Wilson-MacDonald ${ }^{28}$ & 1 & 11 & 4 & Nil \\
\hline Overall & 16 & Mean: 12 & Mean: 15 & Rare \\
\hline
\end{tabular}

Abbreviation: PEMF, pulsed electromagnetic field.

Note: The table does not include cases in which the final outcome of nonoperative management was not reported.

Table 6 Surgical treatment of pediatric scaphoid nonunions found in the literature search

\begin{tabular}{|c|c|c|c|c|}
\hline Surgical technique & Authors & $\begin{array}{l}\text { Number } \\
\text { of cases }\end{array}$ & $\begin{array}{l}\text { Length of postoperative } \\
\text { immobilization }\end{array}$ & Complications \\
\hline \multirow{7}{*}{$\begin{array}{l}\text { Open reduction, } \\
\text { autogenous } \\
\text { bone graft, and } \\
\text { screw fixation }\end{array}$} & Toh et $\mathrm{al}^{29}$ & 35 & Mean: 5.8 wk (4-8) & $\begin{array}{l}\text { Two revision cases, one revision case } \\
\text { restricted movement }\end{array}$ \\
\hline & Masquijo and Willis ${ }^{20}$ & 23 & Mean: 10.3 wk $(8-14)$ & One revision with repeat grafting only \\
\hline & Chloros et $\mathrm{al}^{23}$ & 12 & $13 \mathrm{wk}$ & $\mathrm{Nil}$ \\
\hline & Henderson and Letts ${ }^{31}$ & 11 & $8 \mathrm{wk}$ & $\begin{array}{l}\text { One Herbert screw migrated causing } \\
\text { pain and was thus removed } 14 \text { mo later }\end{array}$ \\
\hline & Mintzer et $\mathrm{al}^{39}$ & 5 & Mean: 4 mo & $\mathrm{Nil}$ \\
\hline & Mintzer and Waters ${ }^{33}$ & 9 & Mean: 2 mo & Nil \\
\hline & ${\text { Littlefield et } \text { al }^{61}}$ & 2 & $3 \mathrm{mo}$ & $\mathrm{Nil}$ \\
\hline \multirow{4}{*}{$\begin{array}{l}\text { Autogenous } \\
\text { bone grafting }\end{array}$} & Henderson and Letts ${ }^{31}$ & 6 & Mean: 4 mo & $\mathrm{Nil}$ \\
\hline & Southcott and Rosman ${ }^{30}$ & 8 & Unknown & One revision grafting \\
\hline & Mintzer and Waters ${ }^{33}$ & 4 & $8 \mathrm{mo}$ & One revision and fixation with K-wire \\
\hline & García-Mata $^{32}$ & 4 & mean: $2.5 \mathrm{mo}$ & One slight restriction \\
\hline \multirow{6}{*}{$\begin{array}{l}\text { K-wire and } \\
\text { autogenous graft }\end{array}$} & Duteille and Dautel $^{24}$ & 11 & $10 \mathrm{wk}$ & $\mathrm{Nil}$ \\
\hline & Henderson and Letts ${ }^{31}$ & 2 & $3 \mathrm{mo}$ & Nil \\
\hline & Maxted and Owen ${ }^{37}$ & 2 & mean: $17 \mathrm{wk}$ & $\begin{array}{l}\text { One required a further procedure to } \\
\text { remove the K-wire, one malunion } \\
\text { with restriction }\end{array}$ \\
\hline & $\mathrm{Nafie}^{36}$ & 1 & Unknown & $\mathrm{Nil}$ \\
\hline & Caputo et a ${ }^{35}$ & 1 & $8 \mathrm{wk}$ & $\mathrm{Nil}$ \\
\hline & Waters and Stewart ${ }^{34}$ & $\begin{array}{l}3 \text { proximal } \\
\text { non-unions }\end{array}$ & $3 \mathrm{mo}$ & One pin-site infection, slight restriction \\
\hline \multirow{3}{*}{$\begin{array}{l}\text { Open reduction } \\
\text { and screw fixation }\end{array}$} & Toh et $\mathrm{al}^{29}$ & 5 & Mean: 6 wk & $\mathrm{Nil}$ \\
\hline & Onuba and Ireland ${ }^{42}$ & 2 & mean: 7 wk & $\mathrm{Nil}$ \\
\hline & Henderson and Letts ${ }^{31}$ & 1 & $2 \mathrm{mo}$ & Nil \\
\hline \multirow{2}{*}{$\begin{array}{l}\text { Percutaneous } \\
\text { screw fixation }\end{array}$} & Toh et $\mathrm{al}^{29}$ & 4 & 3 wk & $\mathrm{Nil}$ \\
\hline & Jeon et $\mathrm{al}^{38}$ & 2 & $3 w k$ & Nil \\
\hline
\end{tabular}

Abbreviation: K-wire, Kirschner wire. 

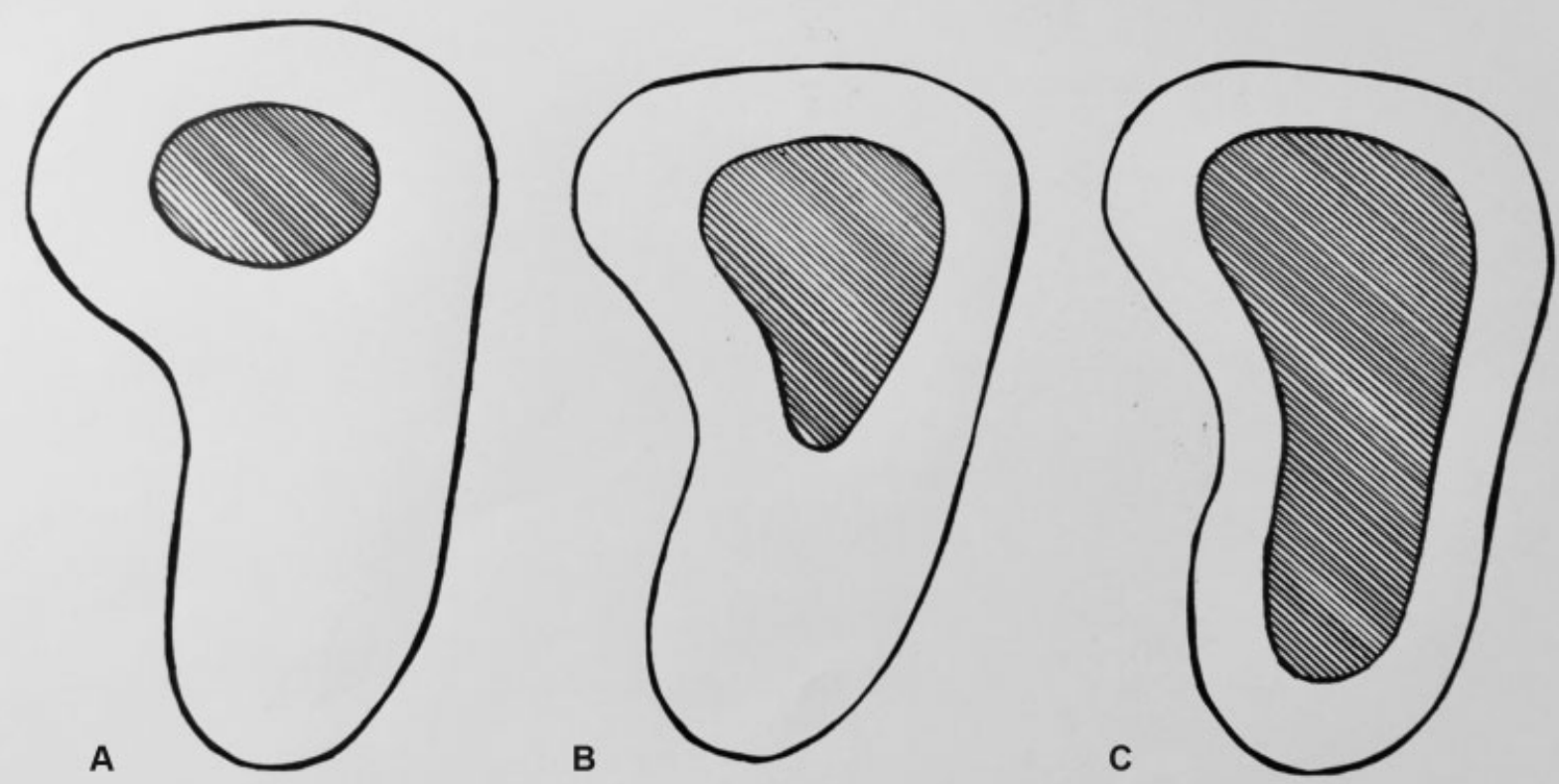

Fig. 3 Scaphoid ossification (dark) in relation to the cartilage cap. (A) At the age of 6 years. (B) At the age of 9 years. (C) At the age of 12 years. ${ }^{20}$

whether the surgeon believes that an internal screw stuck in the growing scaphoid is better than K-wires that can easily be removed after union to have a more normal growing scaphoid.

Surgical management of pediatric scaphoid nonunions should be performed based on clinical and radiographic presentation, noting that there is a chance of remodeling of the pediatric united nonunion ${ }^{4}$ as opposed to the adult situation where scaphoid nonunion will progressively lead to scaphoid nonunion advanced collapse, with radiological signs correlating to the nonunion duration, displacement, and increased scapholunate angles. ${ }^{17}$ The natural history of pediatric nonunions is difficult to document, and it has not been established if the well-described adult long-term complications of nonunions are also true for skeletally immature patients. ${ }^{29,33}$ In fact, it has been reported that dorsal intercalated segment instability (DISI) deformity was spontaneously corrected due to remodeling in a small case series. ${ }^{4}$ The presence of scaphoid humpback deformity and/or DISI deformity may be a stronger indication for surgical intervention in pediatric nonunion cases, ${ }^{17,32,40}$ albeit with weak evidence of such management.

\section{Results and Integrated Discussion}

\section{Review of the Literature: Scaphoid Fractures}

\section{Epidemiology of Scaphoid Fractures}

Pediatric scaphoid fractures are rare injuries ${ }^{41}$ representing between 2 and $3 \%$ of pediatric hand and wrist injuries (-Table 2). ${ }^{1,5,7-9,23}$ It remains the most common carpal bone to be fractured in all pediatric age groups. ${ }^{36}$ Studies revealed an incidence of 0.4 per 100,000 females and 2 per 100,000 males. ${ }^{41-43}$ An 8-year observation of discharge data revealed an incidence of 3 per 100,000 females and 39 per 100,000 males. ${ }^{42,43}$ Pediatric scaphoid fractures usually occur at 11 to 15 years of age, $, 2,7,13,14,17,23$ but fractures have been reported as early as 4 years, though not identified until years later. ${ }^{26}$ Most occur through FOOSH, 2,6,7,12,14,44 during sporting activities, punching and fighting, or road traffic related trauma. ${ }^{1,7}$ It has been suggested that the incidence of scaphoid fractures will rise with the increased popularity of sports such as skiing and skateboarding and the use of recreational punching games machines, possibly also due to an increase in BMI in children. ${ }^{7,13,14,29,45}$ The scaphoid fracture can be associated with other injuries in $15 \%$ of the cases, ${ }^{7}$ such as distal radius fractures (5\%), transscaphoid-perilunate dislocations (1\%), ulnar styloid fractures (1\%), and capitate fractures $(1 \%)^{7}$

Initial radiographs fail to reveal the fractures in 12 to $37 \%$ of the cases ${ }^{1,2,14}$; therefore, many authors choose to treat children with clinical suspicion of scaphoid fracture and negative findings on radiographs conservatively for 2 to 3 weeks. With this management, $30 \%$ of those clinically suspected fractures were proven to be true fractures. ${ }^{2,5,14}$ Around $45 \%$ of the suspected scaphoid fractures have the diagnosis confirmed on the first follow-up, 2 weeks after the injury, and $84 \%$ are evident 5 weeks after injury. ${ }^{2,7}$ It has also been highlighted that MRI had a negative predictive value of $100 \%$ and avoided unnecessary radiation and immobilization in $58 \%$ of patients. ${ }^{1,44}$

\section{Classification of Scaphoid Fractures}

Most pediatric scaphoid fractures are classified and divided by the anatomical fracture site. ${ }^{7}$ The distal third of the scaphoid (avulsion, tuberosity or complete fractures) represent 36 to $87 \%$ of cases (- Table 7). ${ }^{3-7,14,28,31,35,44,45}$ This is in direct contrast to adults, in whom 70 to $80 \%$ of fractures 
Table 7 Anatomical distribution of pediatric scaphoid fractures

\begin{tabular}{|c|c|c|c|c|c|}
\hline Authors & $\begin{array}{l}\text { Number } \\
\text { of cases }\end{array}$ & $\begin{array}{l}\text { Distal third } \\
\text { (avulsion-tuberosity fracture) }\end{array}$ & Distal third & Waist & Proximal third \\
\hline Vahvanen and Westerlund ${ }^{54}$ & 108 & 41 & 53 & 13 & $1^{\mathrm{a}}$ \\
\hline Müssbichler ${ }^{8}$ & 100 & 52 & 33 & 15 & 0 \\
\hline Christodoulou and Colton ${ }^{9}$ & 64 & 21 & 17 & 24 & 2 \\
\hline D’Arienzo $^{47}$ & 39 & 5 & 30 & 3 & 0 \\
\hline Wulff and Schmidt ${ }^{50}$ & 34 & 4 & 18 & 12 & 0 \\
\hline Stanciu and Dumont ${ }^{45}$ & 21 & 2 & 7 & 12 & 0 \\
\hline Total & 366 & 125 & 159 & 79 & 3 \\
\hline Percent & $100 \%$ & $34 \%$ & $43 \%$ & $22 \%$ & $1 \%$ \\
\hline
\end{tabular}

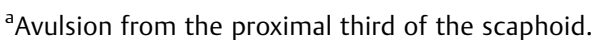

Note: Only published series in which the anatomical location of all cases was revealed are included.

occur in the middle third. Proximal pole fractures occur in 0 to $6 \%$ of the pediatric scaphoid fractures ${ }^{4,5,14,46}$ ( - Table 7 ). This can be explained by the process of enchondral ossification, which progressively occurs eccentrically from distal to proximal after the appearance of the scaphoid ossifying nucleus at 5 years and then further develops until around 13 years in females and around 15 years in males (-Fig. 3) ${ }^{1,6,7,30,37}$

It has been suggested that the cartilage affords protection to the immature carpus, explaining why fewer carpal fractures occur in the pediatric population and occur more frequently in the distal third, which is ossified earlier, particularly in younger children (-Fig. 3). ${ }^{4,5,10,17,23,28,30,37,44-46}$ In older teenagers, with scaphoids near complete ossification, scaphoid fractures more closely resemble the adult pattern (-Fig. 3 ). Consequently, newer literature suggests that $71 \%$ of the fractures of the scaphoid fractures in children and adolescents occur in the waist of the bone, especially in those who have closed physes (84\%). ${ }^{7}$

Another, less used, classification system is based on radiographic features and stage of ossification ${ }^{1,7,47,48}$ :

- Type 1(pure chondral fracture): this occurs in children younger than 8 years and requires MRI or CT to diagnose.

- Type 2 (osteochondral fracture): This occurs between 8 and 11 years of age.

- Type 3 (the most common): this occurs when ossification is almost complete, from the age of 12 years onward.

The retrograde distally based vascular supply to the scaphoid is the same in children as in adults. ${ }^{42,43,49}$ Consequently, many pediatric scaphoid fractures, which involve the well-vascularized distal third pole, unite favorably. A majority of pediatric scaphoid nonunions occur in the middle third of the scaphoid carpus, where healing is more affected by the retrograde vascular supply to the scaphoid. ${ }^{23}$ This also applies to the less common proximal third scaphoid fractures in the pediatric population.

In addition, a greater proportion of scaphoid fractures are undisplaced and unicortical in children, again possibly because of the protective cartilaginous periphery (-Fig. 3). ${ }^{5,8,10,23,30,37,44,45}$ This would explain why the inci- dence of scaphoid fracture nonunion is lower in children, particularly in children below 11 years of age. Our review of the largest published series reveals a $1.5 \%$ rate of pediatric scaphoid nonunions (-Table $\mathbf{3}$ ).

\section{Management of Pediatric Scaphoid Fractures}

\section{Acute Fractures: Undisplaced}

Management of acute undisplaced or minimally displaced pediatric scaphoid fractures should consist of cast immobilization. ${ }^{14,15}$ In children, tuberosity, avulsion, and unicortical fractures require 3 to 6 weeks of immobilization, whereas waist and distal third fractures require 6 to 10 weeks of immobilization. $^{7-9,13,36,45,49,51,52}$ Proximal pole fractures, albeit rare, may require up to 12 to 15 weeks of cast treatment. ${ }^{7,48,51,52}$ However, these are guidelines, and immobilization should be tailored to clinical and radiological signs of healing.

Around $90 \%$ of patients with acute undisplaced scaphoid injuries who are treated with cast immobilization alone achieve a successful union. ${ }^{7,8,13,51,52}$ The type of cast may have an influence on the final results of the treatment of acute undisplaced fractures. Patients treated initially with long arm cast for 6 weeks had a faster healing process ( 9.5 weeks; rate of union: 97\%) than those treated with short arm thumb cast (12.7 weeks; rate of union: $100 \%)^{7,11}$ The mold of the cast to the palm, not its length, has been stated to be the most important factor for fracture healing. ${ }^{11}$ Thus far, it has not been trialed in children if a forearm cast excluding the thumb component, as seen in a randomized controlled trial in adults, will produce the same healing rate as the typical scaphoid cast (including the thumb). ${ }^{51,52}$ Furthermore, advantages of nonoperative management include cost-effectiveness of the treatment and prevention of the negative effects associated with surgery, such as exposition to anesthesia, placement of hardware, possible growth reduction, and risk of infection. ${ }^{11}$ Operative treatment should be reserved for patients at or near skeletal maturity. ${ }^{11}$ Disadvantages of nonoperative management, however, can be the length of immobilization with return to hospital for reviews and the risk of noncompliance in the pediatric patient, as well as nonunion despite adequate immobilization with further surgical treatment. 
Acute Fractures: Displaced

Acute displaced scaphoid fractures in children have not been widely reported. The outcome of nonoperative treatment for displaced fractures may lead to a satisfactory union without complications ${ }^{40}$ but should be looked at as an exception to the general guidelines. ${ }^{53}$ According to evidence-based guidelines and general advice, surgical treatment is indicated for acute displaced fractures to achieve good union rates with less time and quicker return to normal activities. ${ }^{11,15}$ The more specific indication for surgical treatment in pediatric scaphoid fractures, especially in patients near skeletal maturity, is a presence of more than $1 \mathrm{~mm}$ of displacement, fracture comminution, fractures of the proximal pole, delay in diagnosis and initial treatment, poor patient compliance, and a fracture angulation in the sagittal plane with a lateral interscaphoid angle of more than 45 degrees and a height-to-length ratio of more than 0.65 .

There is a trend toward early surgical treatment for undisplaced fractures, as one series showed chronic nonunions in one-third of the patients. ${ }^{14}$ In fact, there are groups suggesting ORIF with screws and bone graft as the first-line treatment even in undisplaced fractures. ${ }^{23}$ We struggle to find any support in the literature for this trend toward surgical management in these benign fractures.

\section{Conclusions and Summary}

Scaphoid fractures are rare injuries in skeletally immature wrists, representing less than $3 \%$ of hand and wrist injuries. As opposed to the skeletally mature patients, the distal third of the scaphoid is extensively affected, and proximal pole fractures are very rare due to the large cartilage cap of the proximal pole (-Fig. 3 ).

Nonoperative management is advised in undisplaced fractures of all kinds and possibly also in displaced fractures due to the remodeling capacity in a growing child. ORIF should be considered in undisplaced fractures with more than $1 \mathrm{~mm}$ of displacement, fracture comminution, involvement of the proximal pole, delay in diagnosis and initial treatment, poor patient compliance, and increased fracture

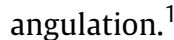

To avoid delayed diagnosis and hence the risk of pediatric scaphoid nonunion, a high suspicion of scaphoid fracture in the injured child should indicate initial X-rays, consideration for immobilization for 2 to 3 weeks, follow-up with repeat clinical assessment, repeat X-rays, and consideration for other imaging modalities (MRI preferred to CT both to minimize radiation and to find associated injuries) as diagnosis may still be unclear up to 5 weeks after injury (-Table 8).

Table 8 The pediatric scaphoid: summary of evidence- and experience-based guidelines based on the literature search and the authors' experience

\begin{tabular}{|c|}
\hline $\begin{array}{l}\text { Initial injury management: } \\
\text { Plaster for } 2-3 \text { wk in patients with negative X-ray but with a high index of suspicion }\end{array}$ \\
\hline Review clinically at 2 to $3 \mathrm{wk}$ and repeat X-ray or consider MRI (preferable) or CT if persistent symptoms \\
\hline $\begin{array}{l}\text { Note: MRI enables to diagnose associated injuries (other occult fractures, bone bruise, joint effusion, etc.), which might lead to } \\
\text { a change of management }\end{array}$ \\
\hline Pediatric scaphoid fractures: \\
\hline Undisplaced: PoP including the thumb (children are very active and will not develop stiffness in these cases) \\
\hline Distal third: review after $2 \mathrm{wk}$, immobilization for up to 3-6 wk \\
\hline Waist - review after 6 wk, immobilization for up to $6-10 \mathrm{wk}$ \\
\hline Proximal pole: review after $6 \mathrm{wk}$, immobilization for up to $12-15 \mathrm{wk}$ \\
\hline Note: younger children ( $<10$ y of age) may need shorter immobilization periods \\
\hline Displaced: ORIF and fixation with K-wires or screws \\
\hline K-wires have to be removed but will allow the scaphoid to grow normally \\
\hline Screws will allow compression but will stay inside the growing scaphoid \\
\hline Delayed or signs of nonunion: MRI or limited CT scan \\
\hline Pediatric scaphoid nonunions: \\
\hline Undisplaced: nonoperative management for 6-12 wk prior to operative management \\
\hline Displaced: ORIF with K-wires or screws \pm bone graft \\
\hline Preoperative planning (in select cases): contralateral imaging and/or three-dimensional printing \\
\hline $\begin{array}{l}\text { Note: the cartilaginous element of a nonossified bone must be taken into account with regard to screw size. Expect } \\
\text { nonstandard imaging intraoperatively }\end{array}$ \\
\hline $\begin{array}{l}\text { Bone graft: distal radius outside growth plates better (no additional donor-site morbidity) than iliac crest outside growth } \\
\text { plates }\end{array}$ \\
\hline
\end{tabular}

Abbreviations: K-wire, Kirschner wire; MRI, magnetic resonance imaging; ORIF, open reduction internal fixation; PoP, plaster of Paris. 
Pediatric scaphoid nonunions are very rare (1.5\%) and are most commonly caused by not only missed injuries but also missed initial diagnosis and treatment. Management of nonunion involves a variety of surgical and nonoperative techniques. Regardless of treatment, excellent outcomes have been reported with surgical and nonoperative management, with few complications, though the duration of immobilization is longer without internal fixation (-Table 8). Our case series clearly shows this.

We would recommend, in conjunction with our presented case series, that in an undisplaced scaphoid nonunion, a period of nonoperative management before surgery ought to be considered. The classic rule, that is, "treat the patient, not the X-ray," is very valid in this age group. If displaced nonunion persists, then surgical fixation and bone grafting have support in the literature (-Table 8). Although all methods have been reported to be successful, we strongly recommend surgeons to use a technique they are familiar with, as demonstrated with our case series.

\section{Funding}

None.

\section{Conflict of Interest}

None declared.

\section{References}

1 Anz AW, Bushnell BD, Bynum DK, Chloros GD, Wiesler ER. Pediatric scaphoid fractures. J Am Acad Orthop Surg 2009;17 (02):77-87

2 Evenski AJ, Adamczyk MJ, Steiner RP, Morscher MA, Riley PM. Clinically suspected scaphoid fractures in children. J Pediatr Orthop 2009;29(04):352-355

3 Huckstadt T, Klitscher D, Weltzien A, Müller LP, Rommens PM, Schier F. Pediatric fractures of the carpal scaphoid: a retrospective clinical and radiological study. J Pediatr Orthop 2007;27(04): 447-450

4 Hamdi MF, Khelifi A. Operative management of nonunion scaphoid fracture in children: a case report and literature review. Musculoskelet Surg 2011;95(01):49-52

5 de Lemos MB, Bentes ÁS, Neto MF, Spinelli LF, Severo AL, Lech O. Pseudarthrosis of the scaphoid in immature skeletons. Rev Bras Ortop 2015;47(03):292-296

6 Torres J, Abat F, Monteiro E, Gelber P. Fracture of the carpal scaphoid in children. Case report and literature review [in Spanish]. Acta Ortop Mex 2013;27(05):335-338

7 Ting B, Sesko Bauer A, Abzug JM, Cornwall R, Wyrick TO, Bae DS. Pediatric scaphoid fractures. Instr Course Lect 2017;66:429-436

8 Mussbichler H. Injuries of the carpal scaphoid in children. Acta Radiol 1961;56:361-368

9 Christodoulou AG, Colton CL. Scaphoid fractures in children. J Pediatr Orthop 1986;6(01):37-39

10 Clarke J, Ramjug S, Barnes S. Established scaphoid nonunion progressing to spontaneous union in a child. Inj Extra 2006;37 (04):170-171

11 Shaterian A, Santos P, Lee C, Evans G, Leis A. Management modalities and outcomes following acute scaphoid fractures in children: a quantitative review and meta-analysis. Hand (N Y) 2019;14(03):305-310

12 Gomes EA, Armanelli F, Saliba GA. Pseudoarthrosis of the tubercle of the scaphoid bone in immature skeleton: case report. Rev Bras Ortop 2015;47(04):513-516
13 Ahmed I, Ashton F, Tay WK, Porter D. The pediatric fracture of the scaphoid in patients aged 13 years and under: an epidemiological study. J Pediatr Orthop 2014;34(02):150-154

14 Gajdobranski D, Zivanović D, Mikov A, et al. Scaphoid fractures in children. Srp Arh Celok Lek 2014;142(7-8):444-449

15 Bae DS, Gholson JJ, Zurakowski D, Waters PM. Functional outcomes after treatment of scaphoid fractures in children and adolescents. J Pediatr Orthop 2016;36(01):13-18

16 Waters PM. Operative carpal and hand injuries in children. J Bone Joint Surg Am 2007;89(09):2064-2074

17 Jauregui JJ, Seger EW, Hesham K, Walker SE, Abraham R, Abzug JM. Operative management for pediatric and adolescent scaphoid nonunions: a meta-analysis. J Pediatr Orthop 2019;39(02): e130-e133

18 Weber DM. Scaphoid fractures in childhood [in German]. Unfallchirurg 2011;114(04):285-291

19 Osterman AL, Mikulics M. Scaphoid nonunion. Hand Clin 1988;4 (03):437-455

20 Masquijo JJ, Willis BR. Scaphoid nonunions in children and adolescents: surgical treatment with bone grafting and internal fixation. J Pediatr Orthop 2010;30(02):119-124

21 Behr B, Heffinger C, Hirche C, Daigeler A, Lehnhardt M, Bickert B. Scaphoid nonunions in skeletally immature adolescents. J Hand Surg Eur Vol 2014;39(06):662-665

22 Fabre O, De Boeck H, Haentjens P. Fractures and nonunions of the carpal scaphoid in children. Acta Orthop Belg 2001;67(02): 121-125

23 Chloros GD, Themistocleous GS, Wiesler ER, Benetos IS, Efstathopoulos DG, Soucacos PN. Pediatric scaphoid nonunion. J Hand Surg Am 2007;32(02):172-176

24 Duteille F, Dautel G. Non-union fractures of the scaphoid and carpal bones in children: surgical treatment. J Pediatr Orthop B 2004;13(01):34-38

25 Geissler WB, Freeland AE. Surgical treatment for fibrous-delayed scaphoid non-unions. In: Buijze GA, Jupiter JB, eds. Scaphoid Fractures: Evidence-Based Management. Philadelphia, PA: Elsevier; 2018:253-268

26 Greene MH, Hadied AM, LaMont RL. Scaphoid fractures in children. J Hand Surg Am 1984;9(04):536-541

27 Weber DM, Fricker R, Ramseier LE. Conservative treatment of scaphoid nonunion in children and adolescents. J Bone Joint Surg Br 2009;91(09):1213-1216

28 Wilson-MacDonald J. Delayed union of the distal scaphoid in a child. J Hand Surg Am 1987;12(04):520-522

29 Toh S, Miura H, Arai K, Yasumura M, Wada M, Tsubo K. Scaphoid fractures in children: problems and treatment. J Pediatr Orthop 2003;23(02):216-221

30 Southcott R, Rosman MA. Non-union of carpal scaphoid fractures in children. J Bone Joint Surg Br 1977;59(01):20-23

31 Henderson B, Letts M. Operative management of pediatric scaphoid fracture nonunion. J Pediatr Orthop 2003;23(03):402-406

32 García-Mata S. Carpal scaphoid fracture nonunion in children. J Pediatr Orthop 2002;22(04):448-451

33 Mintzer CM, Waters PM. Surgical treatment of pediatric scaphoid fracture nonunions. J Pediatr Orthop 1999;19(02):236-239

34 Waters PM, Stewart SL. Surgical treatment of nonunion and avascular necrosis of the proximal part of the scaphoid in adolescents. J Bone Joint Surg Am 2002;84(06):915-920

35 Caputo AE, Watson HK, Nissen C. Scaphoid nonunion in a child: a case report. J Hand Surg Am 1995;20(02):243-245

36 Nafie SA. Fractures of the carpal bones in children. Injury 1987;18 (02):117-119

37 Maxted MJ, Owen R. Two cases of non-union of carpal scaphoid fractures in children. Injury 1982;13(05):441-443

38 Jeon IH, Kochhar H, Lee BW, Kim SY, Kim PT. Percutaneous screw fixation for scaphoid nonunion in skeletally immature patients: a report of two cases. J Hand Surg Am 2008;33(05):656-659 
39 Mintzer CM, Waters PM, Simmons BP. Nonunion of the scaphoid in children treated by Herbert screw fixation and bone grafting. A report of five cases. J Bone Joint Surg Br 1995;77(01):98-100

40 Barton NJ. Apparent and partial non-union of the scaphoid. J Hand Surg [Br] 1996;21(04):496-500

41 Manak P, Drac P, Paucek B. Spontaneous consolidation of scaphoid nonunion in a child. Biomed Pap Med Fac Univ Palacky Olomouc Czech Repub 2008;152(02):271-273

42 Onuba O, Ireland J. Two cases of non-union of fractures of the scaphoid in children. Injury 1983;15(02):109-112

43 Reigstad O, Thorkildsen R, Grimsgaard C, Reigstad A, Rokkum M. Excellent results after bone grafting and K-wire fixation for scaphoid nonunion surgery in skeletally immature patients: a midterm follow-up study of 11 adolescents after 6.9 years. J Orthop Trauma 2013;27(05):285-289

44 Wilson EB, Beattie TF, Wilkinson AG. Epidemiological review and proposed management of 'scaphoid' injury in children. Eur J Emerg Med 2011;18(01):57-61

45 Stanciu C, Dumont A. Changing patterns of scaphoid fractures in adolescents. Can J Surg 1994;37(03):214-216

46 Jernigan EW, Smetana BS, Patterson JM. Pediatric scaphoid proximal pole nonunion with avascular necrosis. J Hand Surg Am 2017;42(04):299.e1-299.e4

47 D'Arienzo M. Scaphoid fractures in children. J Hand Surg Br 2002; 27(05):424-426

48 Elhassan BT, Shin AY. Scaphoid fracture in children. Hand Clin 2006;22(01):31-41

49 Taleisnik J, Kelly PJ. The extraosseous and intraosseous blood supply of the scaphoid bone. J Bone Joint Surg Am 1966;48(06): 1125-1137

50 Wulff RN, Schmidt TL. Carpal fractures in children. J Pediatr Orthop 1998;18(04):462-465
51 Rupani N, Riley N, McNab I. Spontaneous healing of a pediatric scaphoid proximal pole fracture nonunion. J Wrist Surg 2018;7 (01):81-83

52 Buijze GA, Goslings JC, Rhemrev SJ, et al; CAST Trial Collaboration. Cast immobilization with and without immobilization of the thumb for nondisplaced and minimally displaced scaphoid waist fractures: a multicenter, randomized, controlled trial. J Hand Surg Am 2014;39(04):621-627

53 De Boeck H, Van Wellen P, Haentjens P. Nonunion of a carpal scaphoid fracture in a child. J Orthop Trauma 1991;5(03):370-372

54 Vahvanen V, Westerlund M. Fracture of the carpal scaphoid in children. A clinical and roentgenological study of 108 cases. Acta Orthop Scand 1980;51(06):909-913

55 Carlson EJ, Save AV, Slade JF III, Dodds SD. Low-intensity pulsed ultrasound treatment for scaphoid fracture nonunions in adolescents. J Wrist Surg 2015;4(02):115-120

56 Ben-Amotz O, Ho C, Sammer DM. Reconstruction of scaphoid non-union and total scaphoid avascular necrosis in a pediatric patient: a case report. Hand (N Y) 2015;10(03):477-481

57 Iqbal S, Higgins G, Ratcliffe P. Avascular necrosis of both poles of a paediatric was it of scaphoid fracture. Inj Extra 2007;38:247-249

58 Larson B, Light TR, Ogden JA. Fracture and ischemic necrosis of the immature scaphoid. J Hand Surg Am 1987;12(01):122-127

59 Pick RY, Segal D. Carpal scaphoid fracture and non-union in an eight-year-old child. Report of a case. J Bone Joint Surg Am 1983; 65(08):1188-1189

60 Godley DR. Nonunited carpal scaphoid fracture in a child: treatment with pulsed electromagnetic field stimulation. Orthopedics 1997;20(08):718-719

61 Littlefield WG, Friedman RL, Urbaniak JR. Bilateral non-union of the carpal scaphoid in a child. A case report. J Bone Joint Surg Am 1995;77(01):124-126 